\title{
El legado de los mártires de cara al futuro A los 25 años de los mártires de la UCA y a los 35 de Monseñor Romero*
}

\author{
Jon Sobrino, \\ Centro Monseñor Romero, \\ San Salvador.
}

En mis cuarenta años en la UCA he participado en varios congresos de teología. El que ahora comenzamos me parece importante por la variedad y calidad de los ponentes, por la nutrida audiencia proveniente de varios lugares y por la fecha alrededor del 24 de marzo, día de un gran horror y de un gran amor: el asesinato de Monseñor Romero en 1980. Pero sobre todo me parece muy especial por el tema central: "los mártires".

En estas palabras de inauguración no me voy a fijar en el concepto "mártir", sino en la realidad que es previa al concepto. Quiero fijarme en "el martirio" como cosa real. Para ello ofreceré unas breves reflexiones alrededor de cuatro cosas. La primera es la realidad de los "mártires". Una segunda, estrechamente unida a los mártires, es "el pueblo crucificado". La tercera, volver a los mártires "de cara al futuro". La cuarta, cómo hacer real su "legado".

\section{Mártires}

En El Salvador, desde la década de 1970, se habla con naturalidad de mártires. La razón no es que algunos bautizados hayan cumplido los requisitos exigidos por la Iglesia católica para llamarlos así, sino algo más fundamental. Al llamarles mártires hemos querido mostrar públicamente nuestra admiración, también nuestra indignación, y especialmente nuestro agradecimiento por su modo de ser humanos y cristianos. El hecho es espontáneo y popular, pero también reflexivo.

Palabras de inauguración del III Congreso de Teología. 
En síntesis, mártires son mujeres y hombres, que en vida y en muerte se parecieron a Jesús. En detalle, mártires son hombres y mujeres de gran compasión hacia los pobres y oprimidos, y de una verdad insobornable. Molestaron a los opresores y los desenmascararon. Por ello, sufrieron infamia, persecución, represión y murieron asesinados. Derramaron su sangre para que los pobres dejaran de serlo y para que a los oprimidos les llegase liberación. Fueron "mártires de la justicia". En público o en lo escondido, fueron "fieles al Dios en quien creyeron Rutilio y Romero".

Una precisión antes de continuar. Estos mártires "han sido mártires en la Iglesia, pero no [solo] de la Iglesia". Y una confesión. Con ellos hemos experimentado "el paso de Jesús y de su Dios por nuestro mundo".

Por feliz coincidencia, estos días se ha anunciado la beatificación de Monseñor Romero el 23 de mayo y el comienzo del proceso diocesano de beatificación del padre Rutilio Grande, dos símbolos de una pléyade de mártires. En el análisis, los llamamos mártires jesuánicos, en razón de realidades concretas. Según un más y un menos, aman y piensan, sienten y actúan, viven y son asesinados como Jesús de Nazaret. Su fe y esperanza en Dios recuerdan la fe y esperanza de Jesús. Y análogamente al Jesús resucitado, siguen vivos en medio de nosotros.

Los más conocidos son varones. Además de los dos nombrados, en El Salvador murieron asesinados otros quince sacerdotes y el obispo Joaquín Ramos, más una nube de laicos, entre ellos los campesinos Polín y Chus, a quien Monseñor llamaba "el hombre del evangelio". Junto a ellos, fueron asesinadas muchas mujeres. Son conocidas cuatro norteamericanas, Ita, Maura, Dorothy y Jean, raptadas y vilmente ultrajadas antes de ser asesinadas; Silvia Arriola, religiosa salvadoreña; Ticha y las hermanas María Juana y María Ercilla Martínez Flamenco, campesinas catequistas laicas. Recientemente, el arzobispo de San Salvador ha manifestado que se hacen investigaciones sobre la vida y muerte de otros 500 salvadoreños asesinados por causas semejantes, para un eventual reconocimiento de la Iglesia.

La conclusión es que El Salvador, la Guatemala indígena y otros muchos lugares son países de mártires como Jesús. Lo son de forma sobrecogedora, abundante y gloriosa.

\section{El pueblo crucificado}

No mantener vivo lo que acabamos de decir sería humana y cristianamente escandaloso, pero todavía lo sería más ignorar algo más primario y masivo. En número considerablemente mayor que el de los mártires mencionados, muchísimos otros, pobres, campesinos, indígenas, trabajadores con salarios infames, hombres y mujeres sencillos, han muerto asesinados, inocente e indefensamente por el ejército gubernamental, los cuerpos de seguridad, los escuadrones de la 
muerte, al servicio de grandes capitales —en ocasiones, con algún tipo de connivencia de algún jerarca eclesial. Sin incluir ahora las bajas de combatientes de ambos lados, en El Salvador llegan a unos setenta mil, entre ellos grandes mayorías asesinadas en masacres como Las Aradas, El Mozote y el Sumpul. En todo el tercer mundo, son muchos millones. Y la imaginación debe pasar por una conversión para poder revivir las escenas macabras de miles de cadáveres en el fondo del Atlántico, a donde fueron arrojados los opositores de las dictaduras del sur.

De esa mayoría de hombres y mujeres, algunos tenían relación especial con la Iglesia - baste recordar a Manuel Solórzano, un anciano de 72 años, y al niño Nelson Rutilio Lemus, de apenas quince, quienes acompañaban a Rutilio el día del asesinato. Algunos pertenecían a organizaciones populares, a lo cual Monseñor les animaba, siempre que lo hicieran con amor y sin deshumanizarse. La mayoría de las veces, sin embargo, eran campesinos sin especial motivación ideológica, inmensas mayorías en ambos bandos. Con tristeza, decía Monseñor cuál era su anhelo: "lo mismo que les separa es lo que les une: poder llevar comida a sus hijos".

Pobres y oprimidos en vida, inocentes e indefensos en muerte, han quedado sin nombre. $\mathrm{Y}$ aunque suene a alta metafísica, han quedado sin existencia, lo cual también ocurre en iglesias y teologías. Entonces, el escándalo es mayúsculo. ¿Cómo pueden desaparecer sin dejar rastro cientos de millones de seres humanos? Y el escándalo es también teologal. De esos seres humanos dice Puebla que "independientemente de su situación personal y moral, Dios sale en su defensa y los ama".

Cierto es que se han dado pequeños pasos. Hoy se conoce más el número de estos asesinados, que continúan sin nombre. Son 70,000 en El Salvador, 120,000 en Guatemala, tres millones en la República Democrática del Congo, miles en el fondo del Atlántico y del Mediterráneo. Los datos se encuentran en informes de Naciones Unidas y de otras instituciones, pero no hay que llamarse a engaño. Mientras estos números horripilantes no se conviertan en clamor que no deja vivir en paz, los pobres y asesinados seguirán siendo los no-existentes.

Otro pequeño paso ha sido ponerles nombre, el cual, aunque sea genérico, dice algo importante sobre quiénes son: víctimas. Son víctimas de homicidios violentos, de asesinatos selectivos o de masacres, de represión, de indignidad y de tortura. Todo ello, muy frecuentemente, con pasmosa impunidad de los victimarios. Y aunque solo lo mencionemos de paso, son víctimas de homicidios lentos - por hambre y desnutrición. Son los menos tomados en serio, y bien pudieran ser las víctimas más numerosas.

Poner en palabra la realidad de esta mayoría de víctimas, encargarse de ellas y cargar con ellas es la tarea principal de toda pastoral eclesial cristiana. Así lo ha hecho el papa Francisco en Lampedusa, ante un mar lleno de cadáveres. 
Eso no suele ocurrir, y las víctimas quedan sin nombre. Sí ocurrió hace cuarenta años entre nosotros. En Aguilares, tras una masacre de campesinos, Monseñor Romero comenzó a hablar así: "a mí me toca ir recogiendo atropellos y cadáveres". Después, dirigiéndose a los campesinos aterrorizados, que lejos de la iglesia le escuchaban por altavoces, les dijo: "Ustedes son el divino traspasado".

Ignacio Ellacuría ahondó humana y teológicamente en la realidad del pueblo crucificado. Humanamente, afirmó:

Se entiende aquí por pueblo crucificado aquella colectividad que, siendo la mayoría de la humanidad, debe su situación de crucifixión a un ordenamiento social promovido y sostenido por una minoría que ejerce su dominio en función de un conjunto de factores, los cuales, como tal conjunto y dada su concreta efectividad histórica, deben estimarse como pecado ${ }^{1}$.

En otros textos dijo, en lenguaje teológico, que "el pueblo crucificado" es siempre "el signo de los tiempos". Sorprendentemente, añadió que, como el siervo sufriente de Yahvé y como Jesús crucificado, es "portador de salvación”. Y siguiendo su lógica, añadimos nosotros que con el pueblo crucificado, "Dios pasa por nuestro mundo”. Ciertamente, pasó el Dios crucificado.

Hemos diferenciado "mártires jesuánicos" y "pueblo crucificado", pero nunca hay que separarlos, sino que hay que mantenerlos juntos, pues entre ellos hay una intrínseca relación. ¿Por qué acabaron mártires Jesús de Nazaret, Rutilio Grande, Ita Ford, Marianela García Villa? Por salir en defensa del pueblo crucificado, en Galilea, Aguilares y Chalatenango.

\section{De cara al futuro}

Al hablar de mártires, no debemos quedarnos en el pasado, nos dicen con razón. No es posible, y sería absurdo caer en nostalgia de ello, pues nadie en su sano juicio siente nostalgia de cruces y torturas, de madres y ancianos huyendo de noche en guinda. Lo que sí ocurre es que en ese pasado muchos han encontrado un resorte poderoso para poder construir un futuro humano. No hay que ignorar el pasado, ni trivializarlo, ni dilapidarlo.

Los martirios han tenido raíces profundas, y de esas raíces nació una savia. Más que liturgias y muchas oraciones, esa savia ha producido vida, compromiso y esperanza. Los martirios del pasado no han sido "inicios", que pudieran haber desaparecido sin dejar rastro. Han sido "principios" que han principiado realidades importantes en las décadas de 1970 y 1980, y que todavía sigue llegando hasta nosotros en buena manera. Por su naturaleza, los mártires con un mínimo

1. I. Ellacuría, "El pueblo crucificado: ensayo de soteriología histórica", Revista Latinoamericana de Teología, 18 (1989), 318. El texto original es de 1978. 
de cercanía en lugar y tiempo, cercanía que de diversas formas se mantiene al cotejar el pasado con lo que sigue ocurriendo en la historia, no son referentes silenciosos y solemnemente enterrados, sino que son referentes hablantes y actuantes con un dinamismo propio, que ayuda a ver qué caminos hay que recorrer para que haya futuro humano, y cómo mantenerse firmes, sobre todo, cuando lo nuevo tiene mucho en contra.

La institución suele mencionar a los mártires y encarecer su recuerdo. Pero con frecuencia remite a mártires pasados, aunque sea con cariño y devoción, pero con poca capacidad para catapultarnos hacia el futuro. No cualquier pasado tiene la capacidad de hacerlo, pero sí los mártires reales, siempre que les dejemos ser reales, siempre que no les quitemos aristas o no los dejemos languidecer para que no ofrezcan problemas. Este peligro ha sido muy real en el caso de Monseñor Romero, hasta la llegada del papa Francisco.

En El Salvador ha existido una larga tradición de mártires, y en momentos importantes, la tradición tomó una forma específica: unos mártires empujaron a otros. Ya ocurrió en el comienzo del Evangelio, según el relato de Marcos: "Apresado Juan, marchó Jesús a Galilea" (Mc 1, 14). Y tras unos tanteos apostólicos, también Jesús se ve amenazado: "fariseos y herodianos se confabularon para acabar con él" (Mc 3, 6). Al final, ambos murieron asesinados. Y así ocurrió en El Salvador. "Asesinado Rutilio Grande, surgió Monseñor Romero. Asesinado Monseñor Romero, surgió - dijeron muchos - Ignacio Ellacuría”, junto con un considerable número de hombres y mujeres.

Hoy no faltan algunos mártires, pero el destino martirial no ocurre de manera concatenada. Tampoco los mártires son tan notorios, lo cual puede ser históricamente irrepetible. Pero la conclusión no es que no hay que volver a los mártires anteriores. Es ingenuidad pensar que se puede ser seguidor de Jesús en el presente y trabajar para el futuro sin persecuciones - al menos, sufriendo "los oprobios y menosprecios", que decía san Ignacio. De ahí la relevancia de tener presente tradiciones martiriales. $\mathrm{Y}$ ya que he mencionado a san Ignacio - mi venerado patrón-, permítaseme recordar que con los primeros jesuitas en París no se originó una tradición concatenada de mártires. Se originó, indudablemente, otra magnífica tradición. Y sería insensato ponerse a debatir qué tradición ha sido más espléndida, pero sería miope ignorar la tradición de los mártires jesuánicos y la del pueblo crucificado, siervo doliente de Yahvé, tal como ha ocurrido en nuestros días.

Siempre será útil pensar si y en qué medida hay que volver a los mártires de nuestro pasado. Pero hay algo que no podemos olvidar. En medio de "pozos encharcados", en que muchas veces vivimos, necesitamos "fuentes de aguas vivas". Eso es lo que en su día encontramos en Romero y Rutilio, en Maura y Marianela, en señoras de los mercados y en jornaleros cabales. Yendo más atrás, es lo que encontramos en Jesús de Nazaret y en María, madre y buena vecina. 
Esas gentes del pasado nos siguen abriendo los ojos para buscar y encontrar hoy aguas vivas.

\section{El legado}

Legado es lo que tenemos que poner a producir, no sea que escuchemos el reproche de Jesús, en la parábola de los talentos. Tampoco hay que trivializar alegremente el legado, y menos hay que dilapidarlo irresponsablemente, peligros que siempre acechan.

Para poner a producir hoy el legado de los mártires, hay que reconocer en qué mundo lo recibimos. Ese mundo está muy mal. En vísperas de su asesinato, Ellacuría dijo que "nuestra civilización está gravemente enferma"2. Pocos años después, en 2005, J. Ziegler, relator especial de Naciones Unidas para el derecho a la alimentación, dirá que el mundo "está amenazado de muerte por el gran capital financiero". Los elogios de la globalización, miopes, falaces o hipócritamente mantenidos, no han podido ocultar el peligro de "un desenlace fatídico y fatal", que mencionaba Ellacuría. Y en palabras poco conocidas, en 1988 había escrito que no se quiere mirar la verdad del primer mundo, muy visible cuando se mira al tercer mundo, "porque pondría en trance de locura o de conversión toda una forma de ser y hacer"3.

Esta grave enfermedad es originada y mantenida por la civilización de la riqueza. Y para superarla, es necesaria la civilización de la pobreza, palabras escandalosas y en nada políticamente correctas, ni social, ni eclesiásticamente, que el autor mantuvo hasta el final, en contra de comprensibles intentos para suavizarlas. Progresistas bienintencionados repiten que "otro mundo es posible". Ellacuría proclamaría que "otro mundo, muy otro, es necesario".

Junto a la honradez, muchas otras cosas pertenecen al legado de los mártires que hay que mantener. Mencionaré una sola disposición fundamental. "Solo utópica y esperanzadamente uno puede creer y tener ánimos para intentar, con todos los pobres y oprimidos del mundo, revertir la historia, subvertirla y lanzarla en otra dirección". Hoy quisiéramos añadir, "y solo manteniendo el recuerdo de los mártires, como cosa real, tendremos esperanza para cambiar este mundo". Pienso que con ellos tendremos mayor lucidez para pensar los necesarios proyectos históricos, económicos, sociales, políticos, religiosos. Y mayor decisión para llevarlos a cabo.

2. Si no se dice lo contrario, las citas de este apartado están tomadas del discurso que pronunció en Barcelona, el 6 de noviembre de 1989. Ver "El desafío de las mayorías populares", ECA (1989), 493-494.

3. I. Ellacuría, "El reino de Dios y el paro", Concilium, 180 (1982), 593. 
No hay recetas para la esperanza. En lo personal, lo que más me ayuda a la esperanza es el amor de los mártires. En un congreso de mártires, bueno es recordar estas palabras de Jürgen Moltmann: "No toda vida es ocasión de esperanza, pero sí lo es la de aquel Jesús que, por amor, cargó con la cruz". Más conocidas son entre nosotros estas otras de Ignacio Ellacuría: "Con Monseñor Romero, Dios pasó por El Salvador". Juntando ambas, quizás podamos decir para inaugurar este congreso,"No toda vida es ocasión de fe en el misterioso Dios, ni impulso para luchar por la justicia y para vivir con ternura. Pero sí lo es la vida de los mártires con quienes Dios pasó por El Salvador". 